\title{
Estimating thermal conductivity from lithological descriptions - a new web-based tool for planning of ground-source heating and cooling
}

\author{
Claus Ditlefsen, Inga Sørensen, Morten Slott and Martin Hansen
}

It is the overall policy of the Danish Government that by 2050 electricity, heating and transport will be $100 \%$ based on renewable energy. In order to reach this goal a number of different green technologies will have to interact. In areas with no district heating, ground-source heating by heat pump technology (Sanner 2011) could well be one of the solutions.

The potential energy extraction from closed-loop boreholes for ground-source heating depends to a large degree on the thermal conductivity of the surrounding geological formations, although other parameters such as the thermal gradient and the extent of groundwater flow also affect the transport of heat to the borehole. Initial estimates indicate that in Denmark there may be as much as $40 \%$ difference between the most and the least favourable geological conditions, determined by the thermal conductivity of the different sediment or rock types alone (Vangkilde-Pedersen $e t$ al. 2012). Therefore specific knowledge of the thermal conductivity of the geological formations is essential when estimating the optimal drilling depth and the number of boreholes required for a specific plant. In co-operation with research and industrial partners, the Geological Survey of Denmark and Greenland is conducting a three-year project with the title 'GeoEnergy, tools for ground-source heating and cooling based on closed-loop boreholes' (www.geoenergi.org). The objective of the project is to acquire knowledge and develop tools and best practices for the planning, design and installation of shallow geothermal energy systems. This paper describes a web-based tool developed to estimate the thermal conductivity in the area surrounding a potential new plant. The tool was developed within the GeoEnergy project and can be used by administrators, energy planners and drillers of closed-loop boreholes.

\section{Thermal conductivity of shallow Danish sediments}

The thermal conductivity of sediments or rocks depends on their mineral composition, the texture, and the water content. Above the water table, where air is present in the pore spaces, sediments generally have a low thermal conductivity.
Hence information about the position of the water table in the borehole is important when planning a new site.

Relatively few investigations of thermal properties of Danish sediments have been carried out (Balling et al. 1981; Porsvig 1986) and thermal conductivity values published in international literature show broad ranges for the individual sediment types (e.g. Banks 2008; VDI 2010). This is generally the case for clayey sediments and particularly for glacial till, see Vangkilde-Pedersen et al. (2012) for details. Therefore a programme was initiated to investigate the thermal properties of common shallow sediments. The work focused on determining the thermal conductivity of prevalent watersaturated sediments. The range of the thermal conductivities within common sediment types was determined from measurements of 51 samples from well-characterised exposures at different localities (Figs 1, 2). The samples were water saturated in the laboratory and placed in a thermal cupboard at $20^{\circ} \mathrm{C}$ for at least 16 hours before measurements were made. The thermal conductivity was determined using the needle probe method (Wechsler 1992; Hukseflux 2003). Detailed

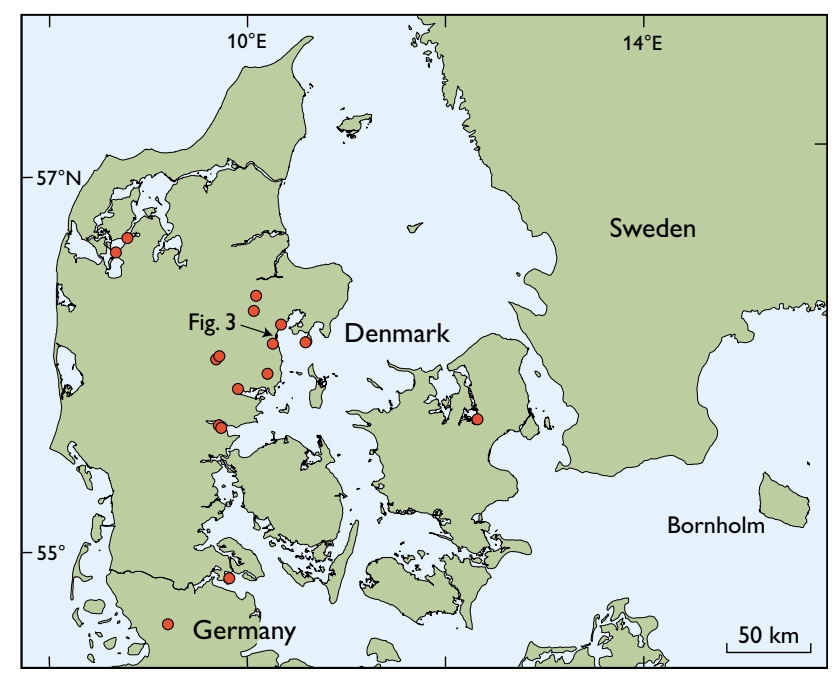

Fig. 1. Map showing sample locations. One sample from northern Germany was kindly provided by Reinhard Kirsch, Landesamt SchleswigHolstein. For sample details see Ditlefsen \& Sørensen (2014). The arrow shows the location of the map included in Fig. 3. 

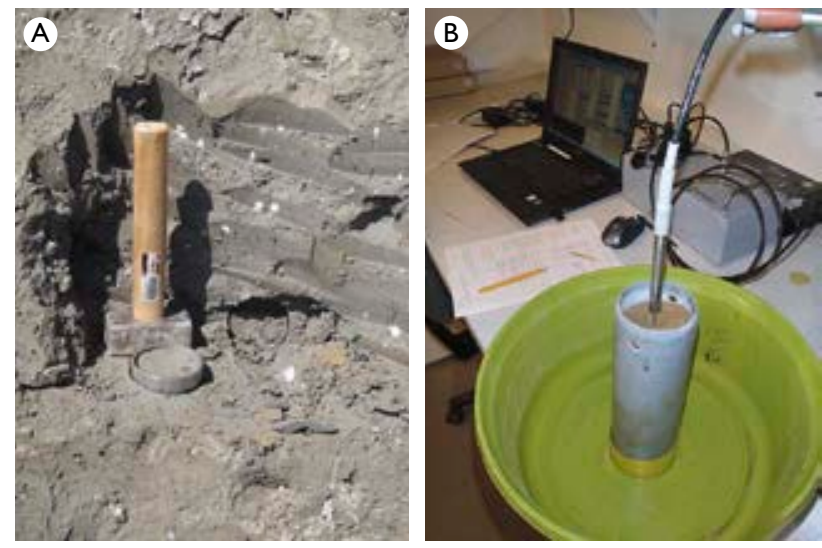

Fig. 2. A: Sampling of clayey till. B: A sediment sample with a needle probe installed.

descriptions of sampling and laboratory procedures, as well as data analysis and statistical analysis were published by Ditlefsen \& Sørensen (2014) and Sørensen et al. (in press). A summary of the results is provided in Table 1. Each sample has been measured 2 to 5 times and an average value representing the sample was calculated. The variation amongst samples of the same sediment type is given as one standard deviation using the average values of each sample. The results indicate that the different sediment types have thermal conductivities within characteristic ranges with one standard deviation corresponding to approximately $20 \%$ of the mean. This further implies that it will be possible to estimate the thermal conductivity around a specific borehole from thorough descriptions of borehole samples alone.

\section{The national borehole database Jupiter}

The Geological Survey of Denmark and Greenland has acquired data on boreholes since 1926 in accordance with the Danish water supply legislation. The data include information about location, construction, geology, water table and groundwater chemistry (Hansen \& Pjetursson 2011). Sam- ples from approximately one third of the boreholes have been described and interpreted by geologists; the rest have been described by drillers in the field. Since 1969, drillers have also been obliged to submit representative borehole samples to the Survey where they are described according to strict standards as outlined by Larsen et al. (1995). In addition, geological interpretations of age and depositional environment are made (Gravesen \& Fredericia 1984). The data are stored in the national borehole database, Jupiter, which can be accessed on the internet free of charge (www.geus.dk). The database includes data on more than 270000 boreholes, corresponding to about six boreholes per square kilometre. In 2001, training and certification of drillers operating in Denmark became mandatory, including instruction in making a simple but rigorous description of borehole samples. This allows for an overall assessment of the character and possible origin of samples that have been described in the field by drillers. All in all, the national borehole database provides planners, drillers and administrators with a unique possibility to evaluate local geological conditions at a given site.

\section{Estimating thermal conductivity values from sediment descriptions}

As described above, it has been possible to establish a relationship between lithology and thermal conductivity for a number of common Danish sediment types. The national database holds a large number of lithological descriptions from throughout the country, and by combining the lithological and thermal conductivity data the borehole database can be used in a new way. To do this it has been necessary to develop a routine that could relate a lithological description to one of the sediment groups in Table 1. This task was facilitated by the structure of the lithological table in Jupiter, where different components of the lithological description e.g. rock type, minor components, mineralogy, grain size, overall interpretation etc. are stored with unique codes

Table 1. Thermal conductivity of some common, shallow, Danish sediments

\begin{tabular}{lcccc}
\hline Sediment type & Number of samples & $\begin{array}{c}\text { Average thermal conductivity } \\
\text { W mk }\end{array}$ & $\begin{array}{c}\text { Range } \\
\text { W mK }\end{array}$ & $\begin{array}{c}\text { One standard deviation } \\
\text { W mK }\end{array}$ \\
\hline Gyttja & 3 & 0.68 & $0.58-0.86$ & 0.15 \\
Smectite-rich clay & 3 & 0.98 & $0.80-1.14$ & 0.17 \\
Silty clay & 10 & 1.15 & $0.90-1.42$ & 0.17 \\
Chalk* & 4 & 1.62 & $1.49-1.80$ & 0.13 \\
Mica-rich, fine-grained sand & 8 & 1.81 & $1.48-2.19$ & 0.27 \\
Till & 19 & 1.89 & $1.40-2.66$ & 0.30 \\
Glacial sand, gravelly & 4 & 2.24 & $1.98-2.43$ & 0.19 \\
Pure quartz sand & 3 & 2.75 & $2.41-3.34$ & 0.51 \\
\hline
\end{tabular}

* Selected data from Balling et al. (1981).

Measurements were conducted with a needle probe (Hukseflux 2008) using water-saturated samples. 
Table 2. Interpretation of thermal conductivity

\begin{tabular}{lcc}
\hline Sediment type* & Supplementary information from driller & Suggested thermal conductivity $\left(\mathrm{W} \mathrm{mK}^{-1}\right)^{\S}$ \\
\hline Sand & & 2.24 \\
Limestone & & 1.62 \\
Clay & Containing, sand, gravel or stones & 1.15 \\
Clay & 1.89 \\
Clay, sand, and stones $\$$ & & 1.89 \\
\hline
\end{tabular}

* Sediment type according to driller.

${ }^{\S}$ The values are based on measurements of thermal conductivity (Table 1) and our interpretations of sediment types.

$\$$ Clay deposits with sand, gravel or stones are interpreted as till. Other clay deposits are interpreted as clay deposited in water.

in individual data fields, which makes rigorous queries into the lithological data possible. In this way most samples described and interpreted by geologists could fairly easily be assigned to one of the sediment groups in Table 1. In addition granite, gneiss and sedimentary rocks found near the surface on the island of Bornholm (Fig. 1) are tentatively ascribed thermal conductivities in accordance with VDI (2010). Water-lain sediments consisting of alternating layers of sand and clay are tentatively ascribed an average thermal conductivity of $1.5 \mathrm{~W} \mathrm{mK}^{-1}$ in accordance with the values for sand and clay (Table 1). For samples where only the overall sediment type was noted by the driller, interpretations had to be made (Table 2). Finally, to compensate for the fact that sediments which are not water saturated have reduced thermal conductivities (VDI 2010), all deposits above the water table in the borehole are tentatively ascribed a conductivity of $1.0 \mathrm{~W} \mathrm{mK}^{-1}$.

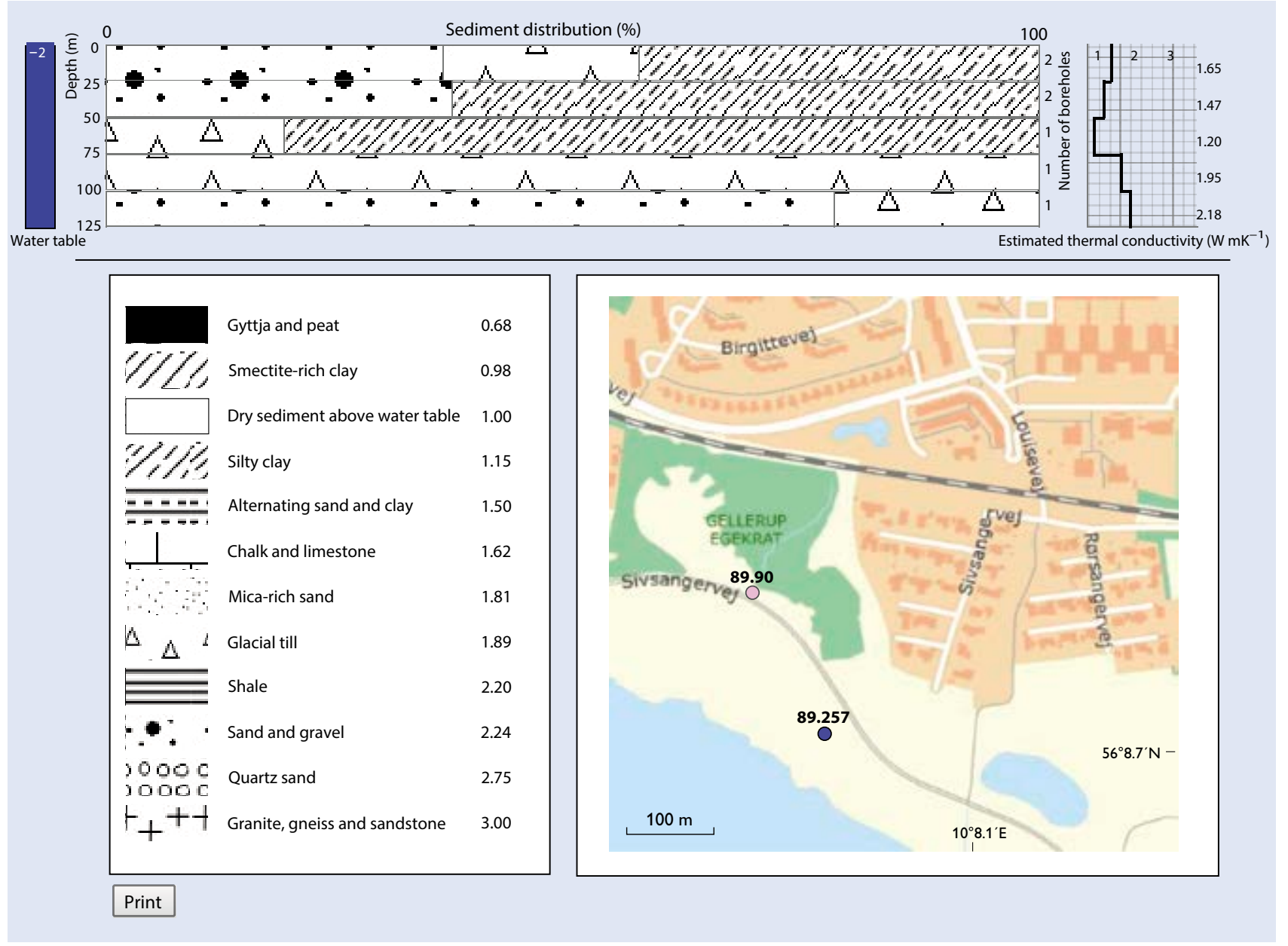

Fig. 3. Results from the web application shown in a standardised report window. http://geuskort.geus.dk/termiskejordarter/ 
It is the intention of the web application to show the expected thermal conductivity in a new project area from existing lithological descriptions and further to show the variation in thermal conductivity with depth as a function of the lithological variations. The calculations include all available boreholes within a user-defined rectangle, and the estimated thermal conductivity is calculated in depth intervals of $25 \mathrm{~m}$ from the available lithological descriptions. Furthermore, it is required that at least $80 \%$ of the interval is covered by descriptions that can be related to a thermal conductivity value. If this requirement is not met, the borehole is excluded from the calculations for the specific depth interval. Within each interval the percentage of each sediment type is then calculated and from this distribution the resulting thermal conductivity of the interval is estimated from the reference values for water-saturated sediments or rocks (Fig. 3). Furthermore, the average depth to the water table is calculated from the most recent soundings in each borehole. Above this depth a reduced thermal conductivity of $1 \mathrm{~W} \mathrm{mK}^{-1}$ is estimated overruling the thermal conductivity related to the water saturated sediment.

The web application is available at http://geuskort.geus. $d k /$ termiskejordarter/. From the initial map, the user can zoom in on the relevant project area and see all boreholes. By using the box search button and clicking on the individual boreholes, a standard lithological report appears and the quality of the individual borehole data can be accessed. By dragging a rectangle over one or more boreholes, calculations based on the selected boreholes are made as described above. In order to obtain a reliable estimate of the thermal conductivity, it is important that the selected boreholes represent the geology at the new site, and a rectangle size of not more than $1 \mathrm{~km}^{2}$ is recommend unless an initial data inspection indicates otherwise.

The results are shown in a standardised report window (Fig. 3). The report shows the average lithological composition of each $25 \mathrm{~m}$ interval as bars and a plot of expected thermal conductivity values versus depth. A plot of the depth to the water table calculated from soundings in the area is shown to the left. The report also contains a locality map that shows the boreholes in the area and a legend that includes average thermal conductivities of different sediment and rock groups. The properties of the different groups can easily be adjusted or more groups can be added by the web administrator when more information about the thermal conductivity of different sediments and rocks becomes available.
So far, the web application has been tested and released. The next step will be to introduce it to different end users such as administrators, drillers and energy planners. We also plan to conduct a number of interviews to get feedback, which may lead to adjustment of the system.

\section{Acknowledgement}

The EUDP programme of the Danish Energy Agency is thanked for financial support of the GeoEnergy project.

\section{References}

Balling, N., Kristiansen, J.I., Breiner, N., Poulsen, K.D., Rasmussen, R. \& Saxov, S. 1981: Geothermal measurements and subsurface temperature modelling in Denmark. GeoSkrifter 16, 176 pp.

Banks, D. 2008: An introduction to thermogeology: ground source heating and cooling, 351 pp. Oxford: Blackwell Publishing.

Ditlefsen, C. \& Sørensen, I. 2014: D6 Overfladenære jordarters termiske egenskaber (in Danish with English summary), 30 pp. http://geoenergi. org/xpdf/d6_jordarters_termiske_egenskaber.pdf

Gravesen, P. \& Fredericia, J. (eds) 1984: ZEUS-geodatabase system. Borearkivet. Databeskrivelse, kodesystem og sideregistre. Danmarks Geologiske Undersøgelse Serie D 3, 259 pp.

Hansen, M. \& Pjetursson, B. 2011: Free, online Danish shallow geological data. Geological Survey of Denmark and Greenland Bulletin 23, 53-56.

Hukseflux 2003: TP02 Non-steady-state probe for thermal conductivity measurement. TP02 manual v1209. Delft: Hukseflux.

Hukseflux 2008: TPSYS02 Thermal conductivity measurement system user manual TPSYS02 manual v0806.doc. Delft: Hukseflux.

Larsen, G., Frederiksen, J., Willumsen, A., Fredericia, J., Gravesen, P., Foged, N., Knudsen, B. \& Baumann, J. 1995: A guide to engineering geological soil description. Danish Geotechnical Society Bulletin 1E, 130 pp.

Porsvig, M. 1986: Varmeovergangsforhold omkring jordslanger. Energiministeriets varmepumpeforskningsprogram 33, $56 \mathrm{pp}$.

Sanner, B. 2011: Concept and feasibility studies. In: Mc Corry, M. \& Jones, G.L. (eds): Geotrainet training manual for designers of shallow geothermal systems, 21-24. Brussels: Geotrainet.

Sørensen, I., Palola, M.A. \& Ditlefsen, C. 2014: D8 Guidelines for equipment, methods and calibration, part 1: Measurement of thermal conductivity. GeoEnergy report, 37 pp. www.geoenergy.dk

Vangkilde-Pedersen, T., Ditlefsen, C. \& Højberg, A.L. 2012: Shallow geothermal energy in Denmark. Geological Survey of Denmark and Greenland Bulletin 26, 37-40.

VDI (Verein Deutscher Ingenieure) 2010: Thermische Nutzung des Untergrundes: Grundlagen, Genehmigungen, Umweltaspekte. Richtlinie 4640, Blatt 1, 33 pp. Düsseldorf: Verein Deutscher Ingenieure.

Wechsler, A.E. 1992: The probe method for measurement of thermal conductivity. In: Maglic, K. D., Cezairliyan, A. \& Peletsky, V.E. (eds): Compendium of thermophysical property measurement methods 2 , Recommended measurement techniques and practices, 161-185. New York: Plenum Press.

\footnotetext{
Authors' addresses

C.D., Geological Survey of Denmark and Greenland, Lyseng Allé 1, DK-8270, Højbjerg, Denmark. E-mail: cd@geus.dk

M.S. \& M.H., Geological Survey of Denmark and Greenland, Øster Voldgade 10, DK-1350 Copenhagen K, Denmark.

I.S., VIA University College, Campus Horsens, Chr. M. Østergaards Vej 4, DK-8700 Horsens, Denmark.
} 